\title{
A Study of Effective Contents of a Comprehensive Health Education Curriculum for Promoting QOL of Obese Children
}

\author{
Naoko Yoshikawa*, Kazuyoshi Ohtsu* and Kohei Yamada* \\ *Health and Sports Science Department, Juntendo University \\ 1-1 Hiragagakuendai, Inba-Mura, Inba-Gun, Chiba 270-1695 Japan \\ ohtsu@sakura.juntendo.ac.jp \\ [Received March 10, 2004 ; Accepted April 11, 2005]
}

\begin{abstract}
The purpose of this study was to examine the effective contents of a comprehensive health education curriculum for promoting QOL of obese children. In cooperation with S. town (Awa County, Chiba Prefecture), we considered effective contents of a comprehensive health education curriculum for promoting QOL. First, practical training was conducted by health specialists including school nurses and public health nurses for the purpose of forming a health education plan for promoting QOL on the PRECEDE Model. Second, in order to examine consistency of needs among the specialists, obese children and their parents, a questionnaire survey about QOL was conducted with elementary school children and their parents in 2002. As a result of this study, it was found that the contents of a comprehensive health education curriculum should include knowledge of the relation between obesity and lifestyle related disease as part of the cognitive domain, should promote self confidence as part of the affective domain, and should promote engaging in outdoor physical activities and participating in community events as part of the psychomotor domain.
\end{abstract}

Keywords: Comprehensive Health Education, Content, Curriculum, Obesity Children, PRECEDE Model

[International Journal of Sport and Health Science Vol.4, 252-264, 2006]

\section{Introduction}

In light of recent notions of life-long health, "HEALTHY JAPAN 21" has been regionally promoted to realize QOL improvement of all people. Health promotion has been taken as one of the strategies to achieve this goal. It is "any combination of health educational and related organizational, economic, and environmental supports for behaviors of individuals, groups or communities conductive to health". It aims to subjectively act on health by improving life habits and foster individual ability for QOL improvement through educational support (health education). It also promotes environmental maintenance by the whole society in order to support subjective enhancement of individual health. In an overview of development of "HEALTHY JAPAN 21" so far, the environment has been well maintained by organizing the life-long health management system. In health education, however, some development has been observed in school health education but not enough in community health education.

School health education is supposed to serve as a footing for life-long health education with a focus on coordination of health education at home and community. Since both juveniles and adolescents spend most of their time at school, school health education is expected to involve students seeking higher education, local residents, and families mediated by students. Coordinated by these three parties, what we call "comprehensive health education" is also appreciated in community health education. To promote comprehensive health education, planning is indispensable. In addition, setting goals and planning content for their achievement are necessary. Formed educational content is called curriculum in English and the course of study in school education. In community health education, curriculum has been greatly underdeveloped and has to be tackled promptly by studying the records of curriculum forming in school health education. 
To solve regional health problems, each municipality prepares a basic plan and accompanying practical action plan [Japan Health Promotion \& Fitness Foundation (1999)]. Because the basic plan sets its final goal by focusing on the outcome, the mainstay should consist of two strategies for health promotion: health education and environmental maintenance. The mainstay for health education, however, has not been adequately established and is intended to be one of the projects executed in the level of action planning. Despite increasing expectations about comprehensive health education for preventing lifestyle related diseases, delayed development of the educational content and subject matter, which greatly affect the outcome of education, hinders its progress in one respect. Management and assessment prerequisites should be incorporated into planning of comprehensive health education to form, execute and evaluate a curriculum by clearly locating it in the basic plan. The curriculum should not be formed by past experiences or in subjectivity but should be logically formed. In this respect, it is worth referring to the PRECEDE - PROCEED Model [Green, et al., (1999); Gold, (1998)], community forming health activity [Fukuda, (1998)], and the Project Cycle Management (PCM) Method [Kojima, (2003)], which are the health development models to promote health. Although each model has advantages and disadvantages, the PRECEDE - PROCEED Model (PPM hereafter) is an activity development model for health promotion and is essential for considering planning of health education as pointed out by Yoshida (1992).

Since the PPM framework is composed on the premise of educational and environmental support, which are the strategies for health promotion, and consists of two sections: PRECEDE Model (PM hereafter), which is the diagnosis and planning processes, and the PROCEED Model, which is the execution and assessment process. PM is concerned with drafting of health education planning. In the first stage, social diagnosis, the needs required for subjects' QOL are examined. In the second stage, epidemiological diagnosis, the needs to the index of subjects' health condition are diagnosed based on scientific data. In the third stage, behavioral and environmental diagnosis, the needs on subjects' lifestyle (life habit and health behavior) and life environment are diagnosed. In the fourth stage, educational and organizational diagnosis, the needs on subjects' lifestyle-related predisposing factors, reinforcing factors, and enabling factors are diagnosed. In the fifth stage, management and policy diagnosis, the needs (problems) to the management aspect in order to realize the needs observed in the first stage through the fourth stage are diagnosed. Then, improvements to these needs are diagnosed from the viewpoint of $5 \mathrm{~W} 1 \mathrm{H}$ : when, where, who, whom, what, and how.

The stages from the first to the fourth are associated with curriculum forming.

The principle of forming a curriculum attaches importance to three areas of need: "national and society needs," "scientific needs," and "learners' needs." The needs obtained by interrelating and synthesizing these areas of need (hereafter referred to as comprehensive needs) through clarification of each need are preferable [Orstein,A.C. (1998)]. Research, however, has not been done in "what perspectives should the three areas of need be diagnosed from?" or "how can we make the diagnosed result of the three areas of need comprehensive?" The PM framework has time series perspectives of educational goals (assessment perspectives) and is logical, and it is effective to incorporate and utilize it to the process of forming a curriculum [Yoshikawa and Ohtsu, (2003)].

It is also effective in making the result of diagnosis of the three areas of need comprehensive to compare the needs diagnosed by specialists, which is the health scientific needs replaced by the specialists' needs, with the learners' and social needs obtained from a questionnaire based on the content of the specialists' needs and to decide the comprehensive needs from the aspects of importance and improvement possibilities.

The procedure to form a curriculum on health education differs in whether a health subject issue, which requires intervention of health education, has been decided or not [Ohtsu, (1977)]. In either case, subject matter should:

1) identify the three areas of need;

2) clarify the comprehensive needs by interrelating these areas of need;

3) set a goal based on the comprehensive needs;

4) set appropriate educational content to achieve the goal;

5) decide subject matter to learn and establish this educational content.

Our health subject issue to form a curriculum is obesity, which is a main risk factor of lifestyle related 
diseases. There have been a variety of studies on obesity from genetic [Endo and Hirano, (2001)], physical [Murata, (2000)], psychological [Matsuoka, (1982)], life [Nagai, et al., (1997)], and nutrition [Shimano, (1996)] aspects. Nevertheless, there are hardly any studies on curriculum forming to improve QOL of obese children.

We obtained cooperation from the "Health Policy Committee" in S Town, Awa County, Chiba Prefecture as our field of research. Obese children in this community (obesity of more than $20 \%$ by the standard weight of the Hibi method [Obesity Diagnose Standard Committee of Japan Obesity Society (2000)] accounted for $25.3 \%$, which was relatively high and double the national average of $10 \%$ in 10 year-olds in 1999 [Minister's Secretariat Survey, Statistic, and Planning Division of Ministry of Education, Culture, Sports, Science and Technology (2003)]. The Health Policy Committee, setting its goal of promoting health education and taking adipositas measures, has been trying to provide preventive education on childhood obesity in cooperation with schools, communities, and families [School Health Nurses Association of Asai District, Awa Branch (2002)]. Despite their efforts, it produced unsatisfactory effects. From this fact, the committee willingly participated in our study with their keen desire to develop a curriculum (educational content and subject matter).

The purpose of this study is to clarify the educational content of comprehensive health education to improve QOL of obese children.

\section{Research Method}

\subsection{Group discussion using the PM worksheet to specialists}

In July, 2002, seventeen members of the Health Policy Committee comprised of 14 school health nurses and 3 public health nurses were divided into two groups of elementary school and junior high school. In this study, we focus on the elementary school group (five elementary school health nurses and one public health nurse). In the preliminary stage of setting a goal of education, we made a needs assessment using the PM worksheet by the following procedure:

1) The specialists fill out the worksheet from the first stage to the fourth stage in what kind of needs obese children may have when they think of them from children's perspectives. The entries of the needs content were corroborated by relative documents and references. Since the specialists had relevant specialized scientific knowledge, the content was regarded as the "health scientific needs."

2) To identify the "learners' needs" we correspond them to the needs of each stage presented by the specialists and make a survey for obese children themselves.

3) To identify the "social needs," we also make a survey for their parents.

\subsection{Survey to elementary school children and their parents}

To examine if the needs content assumed by the specialists in the PM worksheet was consistent with the needs of obese children, a "survey on health" (73 items) was prepared. In September, 2002, after the school health nurses who are members of the Health Policy Committee obtained permission from the school principals, we conducted a "survey on health" and self efficacy scale to 154 students in fourth to sixth grades including obese children, through their class teachers. We collected all surveys on the spot.

To examine if the needs content presumed by the specialists was consistent with the "social needs," we also conducted a survey and self efficacy scale with the parents of the participating elementary school children via the students. We asked the parents to seal the result of the survey and we collected them through the children.

We used the check list consisting of sixteen items presented by Sakano [Sakano and Tojyo, (1986)] for self efficacy.

To analyze the result of the survey, we used the statistical analysis program SPSS for Windows 10.0J.

\section{Result}

\subsection{Result of the group discussion by the specialists' PM worksheet}

As shown in the worksheet in Figure 1, the specialists, imagining obese children, wrote in the first stage "QOL" the following answers to the question, "Describe how the subjects would like to spend an active life."

1) "want to be self-confident"; 


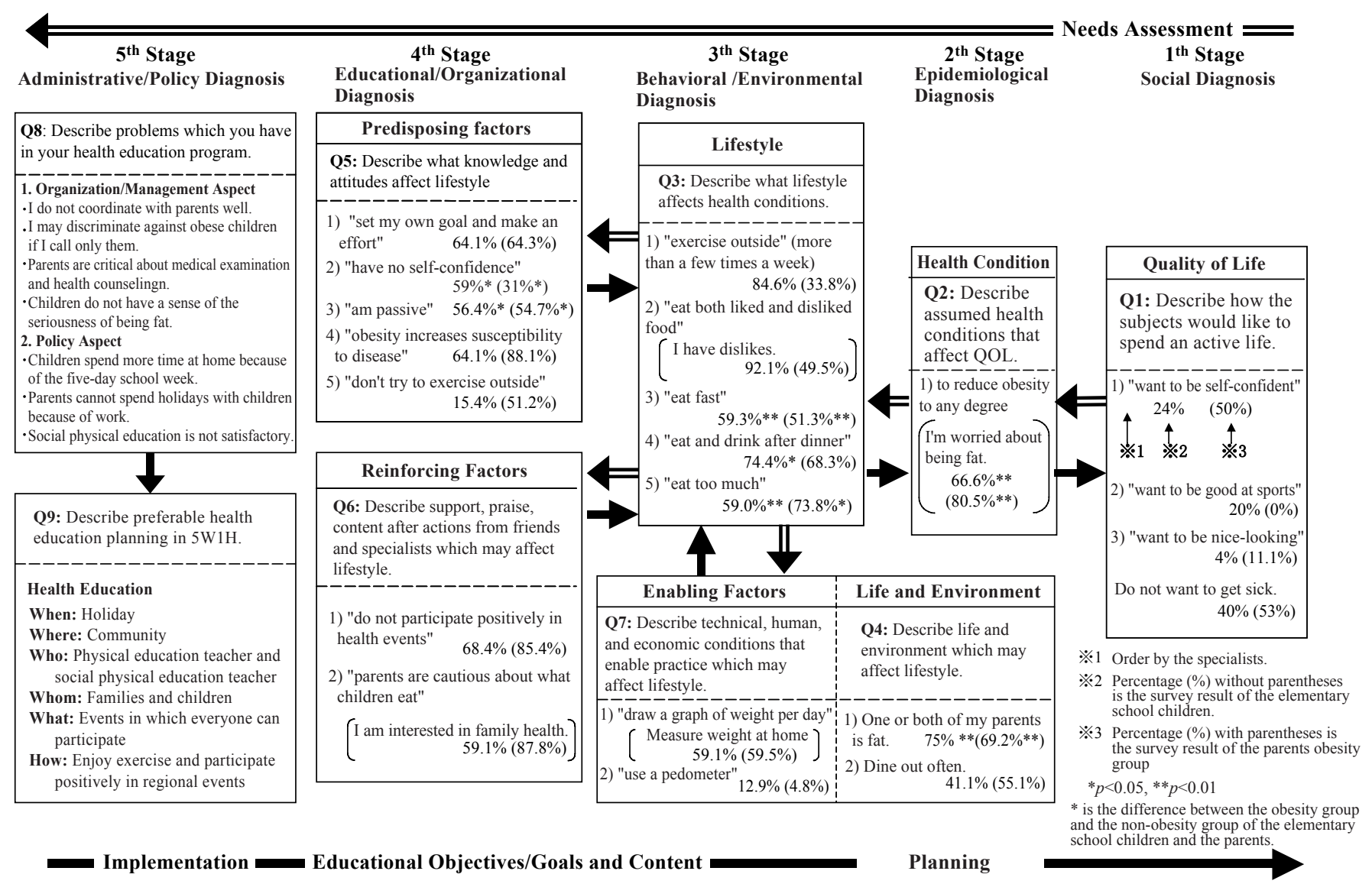

Figure 1 Simple PM Worksheet

PM use is effective to form a logical curriculum. There were many requests for an easier and simpler worksheet which can be completed in a short time than the developed worksheet. Figure $\mathbf{1}$ is the revised simple worksheet for health education planning after many trials.

2) "want to be good at sports";

3) "want to be nice-looking."

In the second stage, "health condition," to the question, "Describe assumable health conditions that affect QOL of the first stage" they answered, "reduce obesity in any degree."

In the third stage, "lifestyle," the answers were:

1) "exercise outside";

2) "eat both liked and disliked foods";

3) "eat fast";

4) "eat and drink after dinner";

5) "eat too much."

In the fourth stage, "predisposing factors," they pointed out:

1) "set your own goal and make an effort";

2) "have no self-confidence";

3) "be passive";

4) "obesity increases susceptibility to disease";

5) "try to exercise outside."

In "reinforcing factors," they presented:

1) "don't participate in health-related events positively";

2) "parents should care about children's meals."

In "enabling factors," the answers were:

1) "draw a graph of weight per day" and

2) "use a pedometer."

\subsection{Result of the needs of the elementary school children by the survey}

The collection rate of the children's survey was $100 \%$ because they were collected on the spot. The valid responses counted 39 obese children (more than $20 \%$ and less than 50\%) and 115 non-obese children.

a) Significant items observed in 39 obese children (obesity group) compared with the 115 non-obese children (non-obesity group) were the following.

1) Your figure: "fat" and "a little fat" obesity group $87.2 \% * * *>$ non-obesity group $19.2 \%$

2) Being fat: "a little worried" and "very worried and want to do something" $66.6 \% * *>34.8 \%$. 
Table 1 Survey Result of Obesity and Non-obesity Group of Elementary School Children

\begin{tabular}{|c|c|c|}
\hline (1)What do you think about your figure? *** & $\begin{array}{l}\text { Obesity } \\
(\mathrm{N}=39)\end{array}$ & $\begin{array}{c}\text { Non-obesity } \\
(\mathrm{N}=115)\end{array}$ \\
\hline Fat & 46.2 & 0.9 \\
\hline A little fat & 41.0 & 18.3 \\
\hline Medium & 12.8 & 45.2 \\
\hline A little thin & 0.0 & 20.0 \\
\hline Thin & 0.0 & 15.7 \\
\hline (2)What do you think about being fat? $* *$ & $(\mathrm{~N}=39)$ & $(\mathrm{N}=109)$ \\
\hline Nothing special & 33.3 & 65.1 \\
\hline I'm a little worried. & 33.3 & 28.4 \\
\hline I'm very worried and want to do something. & 33.3 & 6.4 \\
\hline (3)Do you eat fast? ** & $(\mathrm{N}=39)$ & $(\mathrm{N}=114)$ \\
\hline Very fast & 15.3 & 3.5 \\
\hline Fast & 44.0 & 15.0 \\
\hline Not too fast & 35.6 & 57.0 \\
\hline Slow & 5.1 & 24.5 \\
\hline (4) You are warned that you eat too much. * & $(\mathrm{N}=39)$ & $(\mathrm{N}=115)$ \\
\hline Frequently & 23.1 & 7.8 \\
\hline A little frequently & 35.9 & 15.7 \\
\hline Hardly & 20.5 & 26.1 \\
\hline No & 20.5 & 49.6 \\
\hline (5) The reason you are worried about being fat. & $(\mathrm{N}=25)$ & $(\mathrm{N}=36)$ \\
\hline Do not want to get sick. & 40.0 & 50.0 \\
\hline Want to have self-confidence. $*$ & 24.0 & 8.3 \\
\hline Want to be good at sports & 20.0 & 16.7 \\
\hline Want to be nice looking. & 4.0 & 8.3 \\
\hline (6) How often do you play outside? & $(\mathrm{N}=39)$ & $(\mathrm{N}=115)$ \\
\hline Every day & 43.6 & 34.8 \\
\hline A few times a week & 41.0 & 45.2 \\
\hline Once a week & 12.8 & 17.4 \\
\hline No & 2.6 & 2.6 \\
\hline (7)Do you eat and drink after supper? * & $(\mathrm{N}=39)$ & $(\mathrm{N}=115)$ \\
\hline Every day & 5.2 & 23.9 \\
\hline A few times a week & 35.9 & 31.0 \\
\hline Once a week & 33.3 & 19.5 \\
\hline No & 25.6 & 25.7 \\
\hline (8)Do you have foods you dislike? $\Delta$ & $(\mathrm{N}=39)$ & $(\mathrm{N}=115)$ \\
\hline Yes & 92.1 & 78.9 \\
\hline No & 7.9 & 21.1 \\
\hline (9)Do not set your own goal and make an effort. $\triangle$ & $(\mathrm{N}=39)$ & $(\mathrm{N}=115)$ \\
\hline No & 17.9 & 20.0 \\
\hline Not really & 46.2 & 34.7 \\
\hline Sometimes yes & 17.9 & 33.0 \\
\hline Yes & 17.9 & 9.6 \\
\hline (10)Challenge everything with self-confidence. & $(\mathrm{N}=39)$ & $(\mathrm{N}=115)$ \\
\hline Yes & 41.0 & 49.6 \\
\hline No & 59.0 & 50.4 \\
\hline (11)You're a little passive. $\Delta$ & $(\mathrm{N}=39)$ & $(\mathrm{N}=115)$ \\
\hline Yes & 56.4 & 41.3 \\
\hline No & 43.6 & 58.7 \\
\hline (12)Do not participate in health events. & $(\mathrm{N}=39)$ & $(\mathrm{N}=115)$ \\
\hline Yes & 68.4 & 71.3 \\
\hline No & 31.6 & 28.7 \\
\hline
\end{tabular}

3) "Do you eat fast?": "fast" and "very fast" $59.3 \% * *>18.5 \%$.

4) "You are warned that you eat too much": "frequently" and "a little frequently" 59\%* > $23.5 \%$.

b) The items in which the obesity group (39) showed higher rate than the non-obesity group (115). The underlined items are the items in which the result is reversed.

5) "Are you aware that obesity increases susceptibility to disease?": "Yes" $64.1 \%$ > $59.1 \%$.

6) The reasons why you are worried about being fat. $(\mathrm{N}=$ obesity group 25 ; non-obesity group 36$)$ : "do not want to get sick" $\quad 40 \%<50 \%$;

"want to be self-confident" $24 \% *>8.3 \%$; "want to be good at sports" $20 \%>16.7 \%$; and "want to be nice-looking" $\quad 4 \%<8.3 \%$.

7) "play outside": "Every day" $43.6 \%>34.8 \%$.

8) "Eat and drink after supper": "Every day" $5.2 \%<23.9 \%$.

9) "Have foods which you like and dislike": "Yes" $92.1 \%>78.9 \%$.

10) "Don't set your own goal and make an effort ": "No" and "Not really" $\quad 64.1 \%>54.7 \%$.

11) "Challenge everything with self-confidence": "No" $59 \%>50.4 \%$.

12) "Be a little passive": "Yes" $\quad 56.4 \%>41.3 \%$.

13) "Don't participate in health events": "No" $31.6 \%>28.7 \%$.

14) "Have an interest in family health": "Yes" $59.1 \%>51.3 \%$.

15) "Measure weight at home": "Yes" $59.1 \%>51.3 \%$.

16) "Use a pedometer": "Yes" $12.9 \%>9.6 \%$.

c) The mean scores of the scale of self efficacy measurement were $6.61( \pm 3.43)$ in the obesity group, which were significantly lower than that of the non-obesity group $7.01( \pm 3.48)$. When we examined the scores of self efficacy according to the degree of obesity (every $10 \%$ ) only in the obesity group, the score of self efficacy tended to become lower as the degree of obesity increased.

\subsection{Result of the needs of the parents by the survey}

The number of valid responses of the parents was 62 of obese children and 206 of non-obese children. 
Table 2 Survey Result of Parent Obesity Group and Parent Non-obesity Group

\begin{tabular}{|c|c|c|}
\hline (1)What do you think about your figure? $*$ & $\begin{array}{l}\text { Obesity } \\
(\mathrm{N}=62)\end{array}$ & $\begin{array}{c}\text { Non-obesity } \\
(\mathrm{N}=206)\end{array}$ \\
\hline Fat & 35.5 & 15.7 \\
\hline A little fat & 32.3 & 40.7 \\
\hline Medium & 24.2 & 30.9 \\
\hline A little thin & 4.8 & 9.8 \\
\hline Thin & 3.2 & 2.9 \\
\hline (2)What do you think about being fat? $* *$ & $(\mathrm{~N}=41)$ & $(\mathrm{N}=78)$ \\
\hline Nothing special & 19.5 & 67.9 \\
\hline I'm a little worried. & 53.7 & 29.5 \\
\hline I'm very worried and want to do something. & 26.8 & 2.6 \\
\hline (3)Do you eat fast? ** & $(\mathrm{N}=42)$ & $(\mathrm{N}=86)$ \\
\hline Very fast & 12.8 & 4.4 \\
\hline Fast & 38.5 & 14.0 \\
\hline Not too fast & 43.6 & 57.9 \\
\hline Slow & 5.1 & 23.7 \\
\hline (4) You eat too much. * & $(\mathrm{N}=42)$ & $(\mathrm{N}=86)$ \\
\hline Frequently & 28.6 & 7.0 \\
\hline A little frequently & 45.2 & 48.8 \\
\hline Hardly & 21.4 & 37.2 \\
\hline No & 4.8 & 7.0 \\
\hline (5) The reason you are worried about being fat. & $(\mathrm{N}=34)$ & \\
\hline Do not want to get sick. & 53.0 & \\
\hline Want to have self-confidence. & 50.0 & \\
\hline Want to be good at sports & 0.0 & \\
\hline Want to be nice looking. & 11.1 & \\
\hline (6)Do you exercise and play sports in daily life $\Delta$ & $(\mathrm{N}=42)$ & $(\mathrm{N}=86)$ \\
\hline Every day & 17.1 & 5.8 \\
\hline A few times a week & 16.7 & 12.8 \\
\hline Once a week & 19.0 & 16.3 \\
\hline No & 47.1 & 65.1 \\
\hline (7)Do you eat and drink after supper? $\Delta$ & $(\mathrm{N}=42)$ & $(\mathrm{N}=86)$ \\
\hline Every day & 26.8 & 18.1 \\
\hline A few times a week & 22.0 & 30.1 \\
\hline Once a week & 19.5 & 21.7 \\
\hline No & 31.7 & 30.1 \\
\hline (8) Do you have foods you dislike? $\Delta$ & $(\mathrm{N}=42)$ & $(\mathrm{N}=86)$ \\
\hline Yes & 49.5 & 60.0 \\
\hline No & 50.5 & 40.0 \\
\hline (9)Do not set your own goal and make an effort. $\Delta$ & $(\mathrm{N}=42)$ & $(\mathrm{N}=86)$ \\
\hline No & 9.5 & 21.8 \\
\hline Not really & 54.8 & 56.5 \\
\hline Sometimes yes & 26.2 & 20.6 \\
\hline Yes & 9.5 & 1.2 \\
\hline (10) Challenge everything with self-confidence $\Delta$ & $(\mathrm{N}=42)$ & $(\mathrm{N}=86)$ \\
\hline Yes & 68.2 & 73.3 \\
\hline No & 31.0 & 26.7 \\
\hline (11)You're a little passive. $\Delta$ & $(\mathrm{N}=42)$ & $(\mathrm{N}=86)$ \\
\hline Yes & 54.7 & 52.4 \\
\hline No & 45.3 & 47.6 \\
\hline (12) Do not participate in health events $\Delta$ & $(\mathrm{N}=42)$ & $(\mathrm{N}=86)$ \\
\hline Yes & 85.4 & 83.7 \\
\hline No & 14.6 & 16.3 \\
\hline (13)What are you worried about your chilren's life? & $(\mathrm{N}=42)$ & $(\mathrm{N}=86)$ \\
\hline Do not play outside, insufficient exercise & 36.0 & 29.4 \\
\hline Spend too much on TV games. & 20.0 & 20.6 \\
\hline Sleep late & 8.0 & 17.6 \\
\hline Other & 16.0 & 20.6 \\
\hline
\end{tabular}

a) The items in which the obesity group's parents showed significantly higher rate than the non-obesity group's parents.

1) Your figure: "fat" and " a little fat" obesity group's parents $67.8 \% *$ > non-obesity group's parents $56.4 \%$

2) Being fat: "a little worried" and "very worried and want to do something" $80.5 \% * * *>32.1 \%$.

b) The items in which the parents of the obese children answered that they themselves were fat (42 parents in the obesity group) showed notably higher rate than the parents in the non-obese children who answered that they were not fat ( 86 parents in the non-obesity group) were the following:

3) "Do you eat fast?": "very fast" and "fast" $51.3 \% * *>18.4 \%$.

4) "Eat too much": "frequently" and "a little frequently" $73.8 \% *>55.8 \%$.

c) The items in which the parent obesity group (42) showed a higher rate than the parent non-obesity group (86) were the following. The underlined items were the reversed items.

5) "Are you aware that obesity increases susceptibility to disease?: "Yes" $88.1 \%>$ $87.1 \%$.

6) "Exercise or play sports?": "Every day" $17.1 \%>5.8 \%$.

7) "Eat and drink after supper": "Every day" $26.8 \%>18.1 \%$.

8) "Have foods which you like and dislike": "Yes" $49.5 \%<60.0 \%$.

9) "Don't set your own goal and make an effort": "No"and "Not really" 64.3\% < 78.3\%.

10) "Do everything with self-confidence": "No" $31 \%>26.7 \%$.

11) "Be a little passive.": "Yes" $\quad 54.7 \%>52.4 \%$.

12) "Don't participate in health events": "No" $14.6 \%<16.3 \%$.

13) "Have an interest in family health": "Yes" $87.8 \%>86 \%$.

14) "Measure weight at home": "Yes" $59.5 \%>51.2 \%$.

15) "Use a pedometer": "Yes" $\quad 4.8 \%>1.2 \%$.

16) "What are you worried about your children's life?":

"hardly play outside or exercise" $36 \%>$ $29.4 \%$.

"spend too much time on TV games" $20 \%<20.6 \%$;

"diet " $20 \%>11.8 \%$; 
"sit up late at night" $\quad 8 \%<17.6$;

"others" $16 \%<20.6 \%$.

\section{Discussion}

\subsection{Necessity of selection of educational content in health education}

Educational content necessary to learn at school in Japan is described in the course of study and is revised every ten years. Based on this standard curriculum, every school is intended to form a proper curriculum, or practical curriculum. In the forming process, the educational goal and content presented in the course of study are detailed so as to connect them with actual classwork. It is called the teaching plan......

In the meantime, in community health education, "General Health Education "and "Important Health Education" are designed to be promoted in the Elderly Health Law in 1982. So are "Individual Health Education", "Group Health Education", and "Nursing Home Health Education" in the fourth plan of the Elderly Health Project in 2000. Types and the number of implementations of health education are described in the annual health achievement report, from which some think that health education has progressed. Nevertheless, the internal requirements that form health educational activities, in qualitative aspects including educational goals, content and subject matter, method, and evaluation, have many problems. In other words, it cannot be said that health education is progressing only because we see high numbers from its quantitative data. A hearing survey on health education plan was conducted with fifteen public health and school health nurses and dental hygienists in a study meeting on community health education at a district of Chiba Prefecture in February 2003.

To the question, "Do you know the term 'curriculum'?" everyone responded that they knew the term. To the question, "Do you think that planning is the same as curriculum making?" ten persons answered "I don't know," and three answered "No, I don't think so." To the question, "What kind of anxiety do you have in planning health education?" the answers were the following:

1) educational content (15): "Can I plan content according to my own ideas?"; "Although I have plenty of content, I don't know what I should focus on within a limited time"; "Although I think about presenting a theme of cancer examination, I'm afraid that the subjects may get bored with the same theme every year"; "I don' t know what I should extract as content to be executed in a society of too much information"; "I'm worried how to narrow down the content if the requested theme is big."

2) "evaluation" (13): "I don't know how to assess"; "I don't know how to interpret assessment to group health education"; "I don't know if an effect is originated from health education"; "How many individual goals have been achieved in a group?"

3) "needs from the subjects" (10): "I don't know what the subjects are seeking for"; "I wonder if what we are doing accommodates the residents' needs"; "How should I interpret resident needs which don't match with national policy?"; "I cannot incorporate residents' expectations"; "Residents won't listen when I speak of health."

4) "subject matter" (4): "I cannot obtain subject matter easily"; "I cannot collect materials easily"; "I don't have good VCRs."

From these comments, the active specialists working on health education have various worries, most of which are concerned with curriculum forming and can be solved depending on how they can select appropriate educational content and subject matter.

The conventional one-sided top-down method, which is based on the needs of curriculum providers (specialists), is not effective enough to study and develop curriculum forms of community health education, and it is hoped that the bottom-up method reflecting the needs of subjects (residents) will complement the top-down method [Yoshikawa and Ohtsu, (2002)].

\section{2. $P M$ application and its usefulness}

PM was proposed by Green, et al., in 1974. Since then, it has been applied as the framework of health education planning to solve health issues such as preventing school violence and cancer in western countries [Chaney, et al., (2000)].

In Japan recently, PPM has been regionally applied due to its usefulness for drawing up health education planning against lifestyle related disease and health problems, and its logical planning has been tried 
[Gowma, (2001)]. A PPM-based worksheet helpful for drawing up plans developed by Tounai, et al., [Tounai, (1999)] is used on site and in specialists' trainings. An overview of PPM application tells that many of them mainly focus on environmental maintenance (i.e. health policy). Although PM is supposed to be used in health education, it has hardly been used. In curriculum forming, there has been almost no utilization.

To examine if the people in charge of health education have properly selected educational content and subject matter, we made a focus group interview to three different groups divided from the participants of the above-mentioned community health education training by letting them assume obesity prevention education, asking, "What educational content do you think you should use?" When we compared the result with the views of the PM framework, we found that they lacked life environment, enforcing factors, enabling factors, and QOL. It suggests that curriculum forming by experiences might overlook critical views and that it should be logically formed using the PPM framework.

\subsection{Comprehensive needs procedure and its usefulness}

The PM stages from the first to the fourth show the logical hierarchy (sequence) of the goal of health education. We tried the Tounai worksheet [Tounai, (1999)] in various occasions because of its helpfulness for logical forming of a curriculum. Figure 1 is the revised worksheet for health education planning after many trials upon requests of an easier and simpler worksheet which can be completed in a short time. This worksheet permits logical examination to prepare health education planning alone or in a small group in curriculum forming from the first stage to the fourth stage and in management and policy making at the fifth stage, curriculum execution. In curriculum forming, setting educational goals and content requires clarification of educational needs. Following the above-mentioned procedure of the research method, we incorporated into the PM worksheet (Figure 1) the needs content presented by the specialists and the relevant survey result obtained from the obese children and their parents according to the PM from the first to the fourth stages to compare them. The needs content of the obesity group comprising obese children and their parents showed a notably higher rate or rather higher rate than the non-obesity group of each.

\subsubsection{First stage: Comprehensive needs for QOL}

The specialists exemplified "want to be self-confident" in the first rank, "want to be good at sports" in the second, "want to be nice-looking" in the third, and "do not want to get sick" in the non ranking.

Obese children pointed "want to be self-confident" next to "do not want to get sick" as the reason why they are worried about being fat and showed a higher rate than the non-obesity group even if the rate itself was low. The parents of the obesity group showed a notably higher rate than the parents of the non-obesity group. Matsuoka (1982) mentioned that obese children psychologically do not have self-confidence, whereas the specialists seemed to rightly respond to the questions by taking this point into consideration. Thus, "want to be self-confident" ranks top in all three groups and can be recognized as one of the comprehensive needs.

The other items of "want to be nice-looking" and "want to be good at sports" were not among the responses made by the parent obesity group. It means that the needs of the three parties were not consistent.

Both obese children and the parents obesity group most frequently answered "do not want to get sick" as a reason why they are worried about being fat. No significant difference, however, was observed between the obese group and the non-obese group so it was not acknowledged as one of the needs specific to obese children.

"Want to be self-confident" is recognized by the specialists, obese children and their parents as a comprehensive need for QOL improvement.

\subsubsection{Second stage: Comprehensive needs to health condition}

The specialists ranked "reduce obesity to any degree" at the top. For the obesity group and their parents, a question relating to this item "about your figure" was answered by most of them, "I want to do something" because "I am fat." This desire is notably higher than in the non-obesity group and leads to a desire to reduce obesity to any degree, which explains that the needs of the three parties were consistent. However, because of the lack of clarity of the degree of any in "reduce to any degree," a quantitative 
expression is preferable for goal setting. In the present study, when we examined the decreasing degree of the fourteen subjects with weight loss according to the obesity level of every 0.5 in the obesity measurements in December 2002 and January 2003, we found that the obesity reduction from 1.4 to 1.6 was the highest $(n=4)$. From this result, we regard any of "to any degree" as a quantitative goal.

In $\mathrm{S}$ Town, they have conducted physical measurement, blood tests, adipositas measurement, sphygmomanometry, and sports tests to obese children. If they use these data, "health condition" can be expressed in a quantitative goal. Advance preparation of scientific and objective data is necessary for group discussions using a worksheet.

For example, "HEALTHY JAPAN 21" [Japan Health Promotion \& Fitness Foundation (2000)] described that as a quantitative goal they set obesity to be less than $7.0 \%$ in ten years from the 1997 value of $10.7 \%$. It is preferable for $\mathrm{S}$ Town to prepare a datum of $25.3 \%$ in the rate of obese elementary school children.

The needs to "reduce obesity by 1.4 to 1.6 " relating to the health condition of the specialists, obese children, and their parents is regarded as one comprehensive need.

\subsubsection{Third stage: Comprehensive needs to lifestyle}

The specialists listed "exercise outside" as the first and "eat both liked and disliked foods" as the second. Other non-ranking items include "eat fast," "eat and drink after supper," and "eat too much."

"Exercise outside" was ranked high with the obesity group and their parents but did not observe a significantly difference when compared with the non-obesity group. Shimano (1996), from his study asking obese elementary school children if they had any dislikes, reported that most of the obese children (92\%) answered "Yes," which is consistent with the result of the present study.

Regarding "eat both liked and disliked foods" and "eat fast," both the obesity group and their parents responded "eating fast" distinguishingly more than the non-obesity group. It is important for obese children to "eat slowly and chew food well."

According to Kanda (2000), eating by chewing well has a negative correlation with obesity. A follow-up survey also recognized slow chewing to prevent obesity development. It demonstrates that "eating fast" has a positive relationship with obesity.

"Eat and drink after supper" was frequently responded by the obesity group and their parents without any notable difference between the groups.

"Eat too much" received notably higher responses by the obesity group and their parents than by the non-obesity group.

In this respect, the needs of "eat fast" and "eat too much" relevant to lifestyle of the specialists, obese children and their parents are consistent.

\subsubsection{Fourth stage: Comprehensive needs to Predisposing, Reinforcing, and Enabling factors \\ (1) Predisposing factors}

The specialists enumerated "obese children do not set theire own goal and make an effort ", "do not self-confident," and "be passive." "Do not make an effort by deciding their own goal" showed higher response tendency in both the obesity group and their parents than in the non-obesity group.

Concerning "have no self-confident," both the obesity group and their parents recognized a notable difference compared with the non-obesity group in the survey result of self efficacy scale.

In the response result to the question of "Can you do anything with self-confidence?" both the obesity group and their parents, when compared with the non-obesity group, responded "no" at a high rate, yet with few notable differences. It can be interpreted that they cannot do anything with self-confidence.

In regard to "be passive," when comparing the obesity group with their parents, no significant difference was displayed in the response of "I'm rather shy" in the self efficacy scale survey result while the obesity group more highly answered "Yes" than the non-obesity group. It means that they are not positive. It suggests that positiveness is required for obese children because passivity is regarded as their psychological characteristic.

Thus, the needs of "have no self-confident" relating to predisposing factors of the specialists, obese children, and their parents are consistent.

\section{(2) Reinforcing factors}

The specialists prioritize "don't participate in health-related events positively" and "parents should care about children's meals."

As for "don't participate in health-related events positively," both the obesity group and their parents highly answered "no" without any significant differences. 


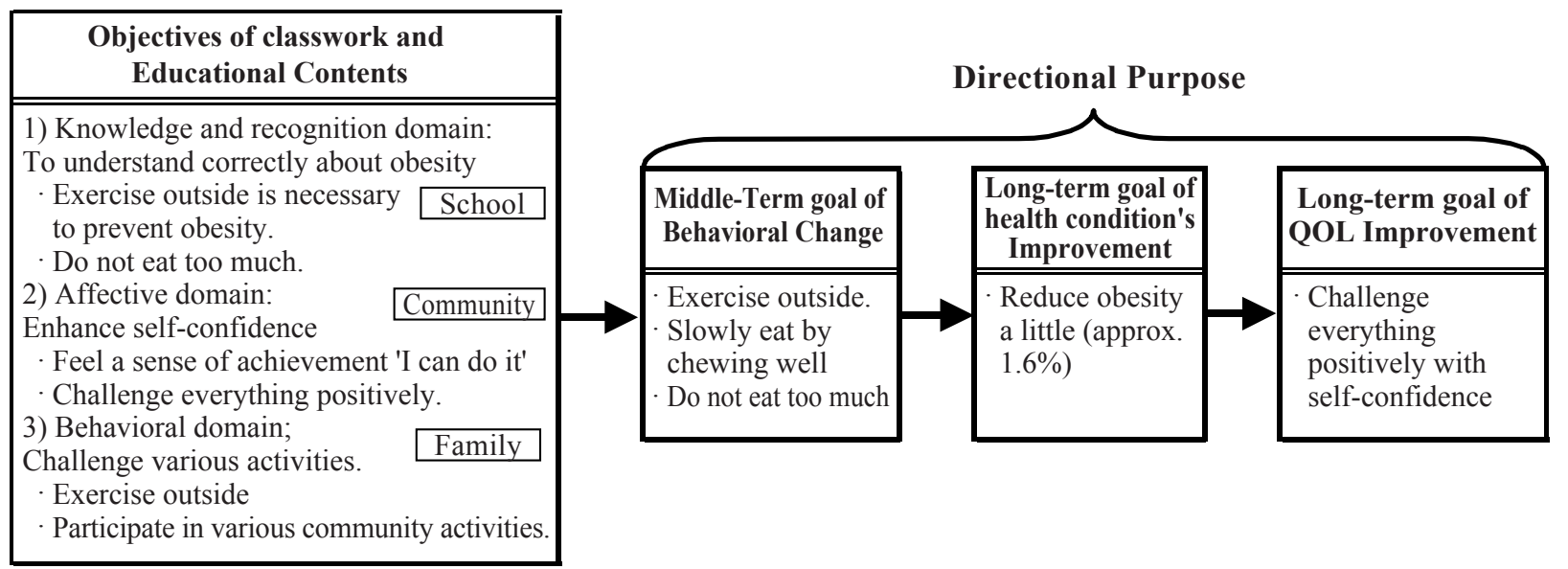

Figure 2 Goals/Objectives and Contents of Comprehensive Health Education

We set the educational goals/objectives and contents based on the expressions of educational goals/objectives and contents described in the course of study.

In relation to "parents should care about children' s meals," the question "Are you interested in family health?" was asked of the obesity group and their parents. Both the obesity group and their parents showed no significant difference when compared with the non-obesity group, but with a higher rate of answering "Yes."

Thus, the needs relating to the reinforcing factors in the specialists, obese children and their parents' response rate was high but not notably different. It means that they were not consistent.

\section{(3) Enabling factors}

The specialists answered "record weight in graph" and "use a pedometer" with a high ranking.

For "record weight in graph," a relevant question to the obesity group and their parents, "Do you measure weight?" was answered "Yes" a little higher by the obesity group than the non-obesity group, yet the rates were low in both groups. According to the specialists, we knew that obese children measure weight every month at school but not at home.

As for "use a pedometer," the obesity group used a pedometer less than the non-obesity group.

Thus, the needs relating to the enabling factors in the specialists, obese children's and their parents' responses are not consistent without any notable differences between the groups even if the response rate was high.

\subsection{Setting of educational objectives/goals and contents}

The first stage to the fourth stage of the PM framework showed the hierarchy (sequence) of the goal of health education. Based on the goal of each stage, the fourth stage corresponds with the goal of classwork, the third stage with the goal of behavior change, the second stage to the goal of health condition improvement, and the first stage with the goal of QOL improvement. To explain these educational goals chronologically, the classwork is a short-term goal(objective), behavior change is a middle-term goal, health condition and QOL improvement are long-term goals. Ogura (1979) sets the directional goal to be "a long-term goal to which the classwork is directing," which corresponds to the first through third stages. Setting this directional goal enables to "more clearly direct what should be emphasized in class" but its assessment is "substantially impossible."

Figure 2 shows the set result of educational goals and contents by comparing characteristics in each stage with the comprehensive needs and referring to the method of expression of educational objectives/goals and contents described in the course of study.

When the goals of education is set, educational contents are set by being specified accordingly. What is generally used in deciding educational content is the goal analysis method adopted by school education - that is, the top-down method in which the educational purpose and goal is sub-divided into sub-goals. Since the goal of education is the status in which the educational content is learned or fixed, or the educational content is conceptualized, the goal analytical method is the process of systemizing the 
educational content. Accordingly, to systemize the educational content, proper educational content and subject matter should be firstly formed to achieve the classwork objectives. However, from the fact that community health education does not have a standard curriculum as school health education does and that it takes a long time to establish it, to systematize it by the bottom-up method, which accumulates forming of the subject matter and educational content and is actually used in real health education, is more realistic. In either case, both methods should be complementarily used.

Because the comprehensive need found in "QOL improvement" in the first stage was "want to be self-confident," we set a directional goal of "challenge everything positively with self-confidence" while we took into consideration the needs and the effect of this stage and referred to the expression of the course of study. Similarly, we set the directional goals in "health improvement" and "lifestyle" as shown in Figure 2. The goal of QOL improvement, "challenge everything positively with self-confidence" is characteristic because it is a single goal which has not been mentioned as a goal in obesity prevention education. By considering these directional goals, the goal of classwork is to be set. Ogura (1979) says that "Documenting the goal of classwork can more clearly identify the content that should be taught in a health class" and that "This goal of classwork is a short-term and correct description about the outcome of classwork, which is cumulatively built up toward a directional goal." Accordingly, documenting (conceptualizing) the educational goal can be regarded as the educational content. In the present course of study, educational content is expressed in concept. For example, the educational content relating to lifestyle in elementary school is described as follows: "To lead a healthy everyday life, a well balanced life of food, exercise, resting and sleep is necessary." The goal of classwork is a feasible goal so that it should be measurably expressed by the use of behavioral verbs. Since the goal domain of classwork is divided into cognitive, affective, and psychomotor domains, the goal of classwork and its educational content should be shown according to these three domains. Therefore, we set the goal of classwork of knowledge and cognitive domain "to correctly understand obesity." We set the educational content to achieve this goal to be "obesity increases susceptibility to disease," "physical exercise outside is necessary to prevent obesity," and "do not eat too much." In the affective domain, we set the goal of classwork to be "enhance self-confidence," and the educational content, "feel a sense of achievement "I can do it'," and "challenge everything positively." In the psychomotor domain, we set the goal of classwork, "challenge various activities." As the educational content, we set "exercise outside" and "participate in various community activities."

In comprehensive health education, it is preferable that school should handle the cognitive domain, home handle the psychomotor domain, and community the affective domain in correspondence to each characteristic of school, and home and community.

In the goal of classwork, the affective (attitude) domain is distinguished in presenting "enhance self-confidence" in contrast to the other two domains, which offer the same as conventional obesity prevention education. Conventional instructions of providing knowledge on obesity or abrupt exercise loading and dieting do not result in good behavior for health. Based on a behavior changing theory called the KAP (Knowledge-Attitude-Practice) model [Ohtsu and Yanagida, (2001)], it is necessary to work on attitude that is a parameter of knowledge and behavior. Attitude has a hierarchy [Ohtsu, (1999)] and as the movement goes from affective attitude, cognitive attitude, to practical attitude, favorable behaviors affecting health are more induced. "Self-confidence" is included in the cognitive attitude and is worth attention as educational content of a facilitating factor toward behavioral change.

The Australian Government [Mosely, et al., (1996) ] developed a health education program in 1993 for children of 5 to $12 \mathrm{yrs}$, which centers on physical activities. They place an importance on heightening physical strength, self-confidence, and self-esteem for children to enjoy active exercise.

\section{Conclusion}

In selecting educational content of comprehensive health education for obese children, we clarify the comprehensive needs by correlating "learner needs," "society needs," and "health scientific needs" based on the PRECEDE Model. Based on these needs, we set the goal of education in direction and classwork.

In regard to the QOL improvement goal as a directional goal, we set "challenge everything positively with self-confidence," as a health 
improvement goal, "to reduce obesity (approx. 1.6\%) a little," as a lifestyle improvement goal, "eat and chew well and slowly," "do not eat too much," and "exercise outside." As the classwork goal, we set "understand correctly about obesity" in the cognitive domain, "foster self-confidence" in the affective domain, and "challenge various activities" in the psychomotor domain.

In educational content to achieve the goal of classwork, "obesity increases susceptibility to disease," "it is necessary to exercise outside to prevent obesity," and "do not eat too much" were clarified in the cognitive domain, "feel a sense of achievement 'I can do it'" and "challenge everything positively" in the affective domain, "exercise outside" and "participate various community activities" in the psychomotor domain.

In comprehensive health education, we decided to handle the cognitive domain at school, the psychomotor domain at home, and the affective domain in the community.

\section{References}

D. Mosely, P. Wooler, et al. (1996). Health education programs centering on physical activities in Australian schools. Japanese Journal of Health Education and promotion, 4, Suppl, 162-163.

Endo, K. and Hirano, C. (2001). Study on the relationship between lifestyle and parents' figure in child obesity. Research of Children's Health, 60 (2), 351-357.

Fukuda, Y. (1998). Importance and problems of community health development activities. Japanese Journal of Health Education and promotion, 5(1), 5-9.

Gouma, E. (2001). Facts of a survey on old age lifestyle needs using the Precede/Procede model. Life Education, 45(10), 25-31.

J W Chaney, et al(2000). An examination using the PRECEDE Model framework to establish a comprehensive program to prevent school violence, American Journal of Health Studies, 16(4): 199-204

Japan Health Promotion \& Fitness Foundation (1999). HEALTHY JAPAN 21: Movement toward national health in the 21st century. Ministry of Health, Labour and Welfare.

Japan Health Promotion \& Fitness Foundation (2000). HEALTHY JAPAN 21: Movement toward national health in the 21st century. Ministry of Health, Labour and Welfare.

Kanda, A. (2000). Child obesity and life-related disease. Japan Medical Journal, 3984, 20-22.

Kojima, M. (2003). How to use PCM. Health Nurses' Journal, 59(11), 1034-1039.

L. W. Green, Marshall W. Kreuter. (1999). Health Promotion Planning: An educational and ecological approach. 3rd ed. Mayfield Publishing Company.

Matsuoka, H. (1982). Psychological Aspects of Obese Children. Pediatrics MOOK, 24:153-163.

Minister's Secretariat Survey, Statistic, and Planning Division of the Ministry of Education, Culture, Sports, Science and Technology (2003). School health statistical survey report 2002, Ministry of Finance Printing Bureau

Murata, M. (2000). How pediatricians find childrens' life-related diseases. Journal of Pediatric Practice, 63(6), 815-821.

Nagai, N., Narutaki, T., and Takegawa, H. (1997). Relationship between secular increase of obese children and life condition at a school in Aioi City, Hyogo Prefecture, Journal of Nutritional Science, 55(1), 39-48.

Obesity Diagnostic Standard Committee of Japan Obesity Society (2000). New obesity judgment and judging criteria of adiposity, Obesity Research, 6, 18-28.

Ogura, M. (1979). Health instruction. Kyoto: Higashiyama Shobo, 18-28.

Ohtsu, K. (1977). Study of curriculum development for health education. Journal of Health and Physical Education of Juntendo University, 20, 37-51.

Ohtsu, K. (1999). Starting from practice in life skill studies: Parallels among issues of smoking, drinking, drugs, sex, etc. 1st ed. Tokyo: Toyo-kan Shuppansha, 172-173.

Ohtsu, K. and Yanagida, Y. (Eds.). (2001). Close-up dietary life series 3: Effective nutrition education - how to promote dietary instructions. Gyosei: 36.

Orstein,A.C.etal. (1998). Curriculum-Foundations, Principles, and Issues (3rd. ed.), A llyn\&Bacon: 201, 237-240.

R S Gold, L W Green, M W Kreuter (1998). EMPOWER. Jones and Bartlett Publishers.

Sakano, Y. and Tojo, M. (1986). General self-efficacy - Trial of scale preparation. Behavior therapy research, 12 (1), 73-82.

School Health Nurses Association of Asai District, Awa Branch (2002). Searching for life-long health education. 9th Sectional Meeting, 52nd Chiba Prefectural Education Seminar: 1-10.

Shimano, A. (1996). On the scene of nutrition instruction Tackling health education to prevent obesity. Health Science, 38(12), 829-833.

Tonai, S. (1992). Model project centering on enhancement of the regional diagnostic function of a healthcare center Practice of health promotion by the PRECEDE-PROCEED model. Research Report 1998 of Public Welfare Science Research Fund, 5-9, 15-24.

Yoshida, T. (1992). PRECEDE/PROCEDE model. Health Science, 34(12), 870-875.

Yoshikawa, N. and Ohtsu, K. (2003). On the development of health education curriculum for obesity-prevention based on PRECEDE- PROCEED Model. Journal of Health and Sports Science of Juntendo University, 7, 24-38.

Yoshikawa, N. and Ohtsu, K. (2003). A study on the development of community health education. Journal of Health and Sports Science of Juntendo University, 6, 1-13. 


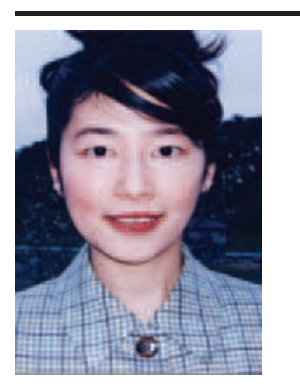

Name:

Naoko Yoshikawa

\section{Affiliation:}

Graduate School of Health and Sports Science, Juntendo University

\section{Address:}

1-1 Hiragagakuendai, Inba-Mura, Inba-Gun, Chiba 270-1695 Japan

\section{Brief Biographical History:}

1999-2001 assistant of Juntendo University

2001- Graduate School of Health and Sports Science, Juntendo University

Main Works:

- Naoko Yoshikawa and Kazuyoshi Ohtsu, A Study on the Development of Community Health Education, Part 1-Evaluation based on the Management Cycle about Community Health Education's Implementation for Three Years in a Town in Chiba-, Journal of Health and Sports Science Juntendo University, 7:24-38.

- Naoko Yoshikawa and Kazuyoshi Ohtsu, On the Development of the Health Education Curriculum for Obesity-Prevention Based on PRECEDE-PROCEED Model, Journal of Health and Sports Science Juntendo University, 6:1-13.

Membership in Learned Societies:

- Japanese Society of Health Education and Promotion

- The Japanese Association of School Health 